\title{
La tradition européenne du sonnet, études réunies par P. LABARTHE et J. BARTUSCHAT
}

\section{Maurizio Busca}

\section{(2) OpenEdition}

\section{Journals}

\section{Edizione digitale}

URL: https://journals.openedition.org/studifrancesi/22521

DOI: 10.4000/studifrancesi.22521

ISSN: 2421-5856

\section{Editore}

Rosenberg \& Sellier

\section{Edizione cartacea}

Data di pubblicazione: 1 avril 2020

Paginazione: 165

ISSN: 0039-2944

\section{Notizia bibliografica digitale}

Maurizio Busca, «La tradition européenne du sonnet, études réunies par P. LABARTHE et J. BARTUSCHAT», Studi Francesi [Online], 190 (LXIV | I) | 2020, online dal 01 avril 2020, consultato il 03 août 2021. URL: http://journals.openedition.org/studifrancesi/22521; DOI: https://doi.org/10.4000/studifrancesi. 22521

Questo documento è stato generato automaticamente il 3 août 2021

\section{cc) (i) (2)}

Studi Francesi è distribuita con Licenza Creative Commons Attribuzione - Non commerciale - Non opere derivate 4.0 Internazionale. 


\title{
La tradition européenne du sonnet, études réunies par P. LABARTHE et J.
}

\section{BARTUSCHAT}

\author{
Maurizio Busca
}

\section{NOTIZIA}

La tradition européenne du sonnet, études réunies par P. LABARTHE et J. BARTUSCHAT avec la collaboration de M. ALBERTINI, S. FERRILLI et N. VITTOZ, Genève, Slatkine Érudition, 2019, $286 \mathrm{pp}$.

1 Il sonetto, come sottolineano i curatori del presente volume, è stato per secoli un potente vettore di scambi letterari e culturali translinguistici e transnazionali. I dodici studi qui riuniti affrontano alcuni aspetti della sua immensa storia europea (soprattutto italiana, francese, tedesca e inglese), insistendo sulle dinamiche di circolazione e appropriazione di elementi formali e tematici elaborati in contesti linguistici e culturali differenti e sui fenomeni di continuità e rottura nella ricezione di singoli testi o di canzonieri. I contributi raccolti sono i seguenti.

Johannes BARTUSCHAT et Patrick LABARTHE, Avant-propos, pp. 7-9; Olivier POT, Le "poème en sonnets». Considérations variées sur un dispositif sériel, pp. 11-45; Stefano PRANDI, «Rime Sparse»: il sonetto proemiale dai "Fragmenta" alla lirica rinascimentale, pp. 47-80; Katia SENJIC, Luigi Alamanni, le sonnet italien en terre française et les enjeux de l'écriture, pp. 81-94; Marco VENEZIALE, Sonnets, presque sonnets et structures: quelques notes autour du manuscrit Chantilly, Musée Condé, pp. 95-108; Pascale DROUET, Shakespeare et le sonnet: «To put fair truth upon so foul a face?», pp. 109-122; Itzíar LÓPEZ GUIL \& GRUPO z, L'autoréflexion implicite chez deux maitres espagnols du sonnet: Francisco de Quevedo et Blas de Otero, pp. 123-141; Antonio SÁNCHEZ JIMÉNEZ, Lope de Vega et le cheval de Séius: les sonnets du "Laurel de Apolo" (1630), pp. 143-163; Jean-Noël PASCAL, Lazare Carnot (1753-1823), poète oublié et sonnettiste anachronique, 
pp. 165-182; Dominique BILLY, "Bien loin d'ici" et ses modèles, pp. 183-221; Julie ABREUDEKENS, L'ouvert et l'origine: étude du sonnet dans les "Sonnets à Orphée" de Rainer Maria Rilke, pp. 223-238; Peter FRÖHLICHER, Sonnets à quatre voix: un 'renga' occidental, pp. 239-251; Patrick LABARTHE, Bonnefoy et le sonnet comme anamnèse, pp. 253-269.

I quattro interventi che aprono il volume guardano al Cinquecento francese. Le analisi di Pot muovono da considerazioni sulla difficoltà di collocare il sonetto nel quadro dei generi letterari di ascendenza sia medievale che aristotelica, difficoltà che il Rinascimento supera attraverso l'adozione della forma canzoniere (che introduce la possibilità di assegnare una funzione narrativa - e mimetica - ai componimenti lirici). Vengono quindi studiati i caratteri strutturali di un ampio corpus di raccolte apparse fra la metà del XVI secolo e la metà del XVII, rilevando come la tendenza diffusa alla trasgressione delle simmetrie interne nei canzonieri apparsi dopo l'olive e le prime Amours ronsardiane sia riconducibile alla ricerca di un equilibrio fondato su una concordia discors dei singoli elementi che compongono l'opera (l'A. parla, a questo proposito, di un «réglage de déréglements», p. 25). Prandi si concentra invece su un luogo di capitale importanza per i canzonieri rinascimentali di ispirazione petrarchista: il testo proemiale. Conducendo una ricognizione parziale presso autori italiani, spagnoli, francesi (Scève e Desportes) e inglesi, l'A. osserva come, anche nei casi in cui la ripresa di RVF I è più esplicita, i poeti analizzati tendano generalmente a valorizzare elementi estranei alla logica petrarchesca. Senjic dedica il suo contributo alle Opere toscane di Alamanni, pubblicate da S. Gryphe nel 1532-1533. Dopo aver ricordato il ruolo assunto da Francesco I nella realizzazione di questa impresa editoriale e la natura dei legami fra il monarca e il poeta, l'A. si interessa alle sezioni di sonetti «scritti al christianissimo re Francesco Primo» (in particolare OT II, 31), in cui l'encomio si nutre di evidenti allusioni alla biografia petrarchesca. Infine, Veneziale prende in esame il ms. Chantilly, Musée Condé, 523 (ca. 1540), contenente circa cinquecento liriche di diversi autori fra cui Mellin de Saint-Gelais, i cui componimenti occupano l'intera sezione finale del manoscritto. Sulla base di osservazioni di carattere materiale e strutturale, l'A. propone di riconsiderare l'estensione e la natura della sezione finale, arretrandone il punto d'inizio (formulando così l'ipotesi che la paternità di due poesie anonime e di un'epistola finora attribuita al cardinale di Tournon sia dello stesso SaintGelais) e attribuendogli lo statuto di autentico canzoniere elaborato dal poeta stesso (che l'avrebbe inserito nel manoscritto al momento della sua revisione). 